reinforce the 'community is good, hospital is bad' divide, which often continues to pervade the thinking of politicians, users and professionals. Furthermore, I believe that one of the greatest strengths of our current system in Grampian is that consultants are made responsible and accountable for their bed usage and thus are also seen as responsible for ensuring adequate community provision wherever possible.

However, for a variety of reasons, the continuum model, which I believe we have successfully offered in Grampian, unlike other parts of Scotland, over many years is now under threat from a number of different sources. These include local management changes, a continued belief from the Scottish Executive that community mental health services are in some way completely separate from hospital mental health services, and thus can be aligned with social care and other services, and from the new Mental Health Act in Scotland, which from 1 April 2005 will undoubtedly push consultant psychiatrists into much more of a pure secondary care situation. It has the potential to completely exclude the general practitioner from the detention process and emphasises repeated appeal against detention in the form of Tribunals.

This may lead to the situation that Dr De Silva describes under his joint working model, in which the consultant psychiatrist has a caseload of a low number of complex, often dual diagnosis patients. Yet I fear for many psychiatrists such as myself that this will be a retrograde step, which will be at the detriment of the very close links that we have achieved with primary care through our aligned services. It will make it much harder for us to work with general practitioners in an educational way, to offer early intervention and adequate management to patients with a variety of psychiatric conditions, and thus to continue to limit our usage of acute psychiatric beds to which admission should be seen as part of an ongoing continuum of care, led by the responsible consultant psychiatrist rather than being seen as a separate process that continues to reinforce the unhelpful hospital $v$. community divide.

Alastair N. Palin Consultant in Adult Psychiatry/ Clinical Director, Royal Cornhill Hospital

\section{Less stress or more?}

Dr Hampson must be congratulated for the very real achievement of modernising her job plan (Psychiatric Bulletin August 2003, 27, 309-311). It is surely right to maximise the efficient use of consultant time by excluding routine tasks that can be safely delegated. I wonder however if the new job plan might not be even more stressful for the consultant than before.

My reservation is around the area of 'supervision' of other disciplines and the role of advisor to GPs, a role that involves 'hearing about patients' rather than seeing them.

The processes for communicating a clinical problem involve presenting a short summary of the patient, usually verbally, lasting maybe 5 minutes. It is similar perhaps to the 'elevator pitch' used in the film industry to outline a movie proposal to a prospective producer.

Listening to the elevator pitch is wearing for the recipient (particularly if the metaphorical elevator is a slow one or seems to belong to an unusually tall building). The effect is similar to a PMP exam, where a series of hypothetical problems is laid before the candidate.

Many of the telephone and verbal vignettes may be risk reduction transactions rather than genuine requests for advice. As such they are more likely to be generated by less confident or skilled practitioners, who are also less likely to be proficient at summarising key points. In the new way of working the consultant may increasingly serve as a risk depository. Am I alone in finding delegated working more stressful than direct patient contact?

Tim O'Grady Clinical Tutor for Lincolnshire, Peter Hodgkinson Centre, Lincoln LN2 5UA

\section{Multi-disciplinary team assessments}

The article by Simpson and De Silva in the September issue (Psychiatric Bulletin, September 2003, 27, 346-348), outlining two team referral models of multidisciplinary teams (MDT) working in Old Age Psychiatry, was of interest to us, primarily as the debate echoed changes which have occurred within our own service within the past few years. However, we believe that we have moved the service one important step further.

Until August 2002, the Old Age Service in Eastern Hull, a socially deprived urban area, worked largely by the 'Whitby model' described in the article. However, despite this model, a large catchment population, high morbidity and referral rates (including many inappropriate 'urgent' referrals), demanding cover arrangements, and the relative clinical isolation resulting from working in scattered community settings, all contributed to sustained stress and low consultant job satisfaction.

In response, the service was remodelled to involve two consultant psychiatrists working closely together. Although one of the consultants takes the lead for a rural population, both have input into urban Eastern Hull and work as integrated members of the MDT. Each has an area of special interest across the whole patch - one consultant deals with hospital liaison, while the other leads the memory clinic and family therapy. Protected time is provided for $C P D$, personal and service development issues.

The incorporation of this arrangement into MDT working has, we believe, improved the depth and quality of discussion on clinical issues, cover is simple, and consultant job satisfaction has vastly improved. The MDT values the model and we believe that overall service quality has improved. Others may wish to consider similar service innovations.

David Lawley \& John Bestley Consultants in Old Age Psychiatry, Hull and East Riding Community Health NHS Trust, Maister Lodge, Hauxwell Grove, Middlesex Road, Hull HU8 ORB 